\title{
WestVirginiaUniversity
}

THE RESEARCH REPOSITORY @ WVU

West Virginia Agricultural and Forestry Experiment

Davis College of Agriculture, Natural Resources

Station Bulletins

And Design

$1-1-1965$

\section{A method for controlling the dimension of hardwood lumber}

Norman D. Jackson

C. B. Koch

William H. Reid

Follow this and additional works at: https://researchrepository.wvu.edu/ wv_agricultural_and_forestry_experiment_station_bulletins

\section{Digital Commons Citation}

Jackson, Norman D.; Koch, C. B.; and Reid, William H., "A method for controlling the dimension of hardwood lumber" (1965). West

Virginia Agricultural and Forestry Experiment Station Bulletins. 511.

https://researchrepository.wvu.edu/wv_agricultural_and_forestry_experiment_station_bulletins/475

This Bulletin is brought to you for free and open access by the Davis College of Agriculture, Natural Resources And Design at The Research Repository @ WVU. It has been accepted for inclusion in West Virginia Agricultural and Forestry Experiment Station Bulletins by an authorized administrator of

The Research Repository @WVU. For more information, please contact ian.harmon@mail.wvu.edu. 
West Virginia University Libraries

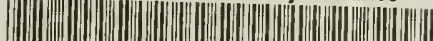


Digitized by the Internet Archive in 2010 with funding from

Lyrasis Members and Sloan Foundation

http://www.archive.org/details/methodforcontrol511jack 


\section{A METHOD FOR} CONTROLLING THE

\section{DIMENSION OF}

\section{HARDWOOD LUMBER}

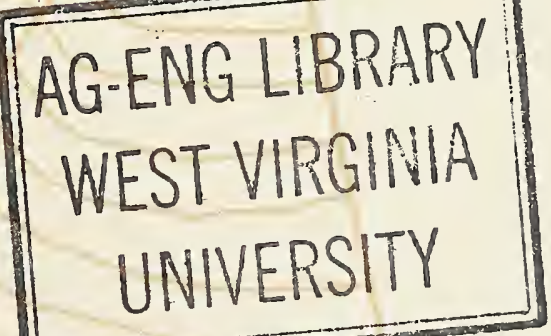

WEST VIRGINIA UNIVERSITY 


\section{THE AUTHORS}

The authors of A Method for Controlling the Dimension of Hardwood Lumber are Norman D. Jackson, Christian B. Koch, and William H. Reid. Mr. Jackson is Assistant Wood Scientist; Dr. Koch is Associate Wood Scientist; and Mr. Reid, formerly on the staff of the Division of Forestry, is now with Forest Products Marketing Branch, Division of Forest Economics and Marketing Research, USDA, Forest Service, Washington, D. C.

West Virginia University

Agricultural Experinient Station

College of Agriculture, Forestry, and Home Economics

A. H. Vanlandinghair, Director

Morgantown 


\section{Contents}

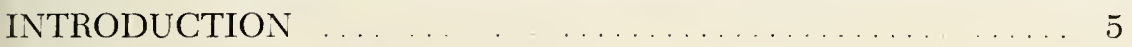

THE NATURE OF VARIATION IN LUMBER THICKNESS . . . . 6

THE PREPARATION AND INTERPRETATION OF

QUALITY CONTROL CHARTS $\ldots \ldots \ldots \ldots \ldots \ldots \ldots \ldots$

The Selection and Measuremient of Subgroups $\ldots \ldots \ldots \ldots \ldots$

The Chart for Averages $\ldots \ldots \ldots \ldots \ldots \ldots \ldots \ldots \ldots$

The Chart for Ranges $\ldots \ldots \ldots \ldots \ldots \ldots \ldots \ldots \ldots \ldots \ldots$

Calculation of Control Limits $\ldots \ldots \ldots \ldots \ldots \ldots \ldots \ldots$

Interpreting Control Charts $\ldots \ldots \ldots \ldots \ldots \ldots \ldots \ldots \ldots$

CASE STUDIES OF QUALITY CONTROL APPLICATION ..... 15

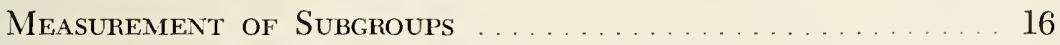

Trial Control Charts $\ldots \ldots \ldots \ldots \ldots \ldots \ldots \ldots \ldots \ldots \ldots \ldots$

Examples of Control Charts $\ldots \ldots \ldots \ldots \ldots \ldots \ldots \ldots$

Discussion . . . . . . . . . . . . . . . . . . . . . 25 



\section{A METHOD FOR \\ CONTROLLING THE DIMENSION OF HARDWOOD LUMBER}

Norman D. Jackson, Christian B. Koch, and William H. Reid

\section{Introduction}

THE GRADE and ordinarily the selling price of a hardwood board is 1 determined by the percentage of clear face material that can be cut from it by crosscutting, ripping or both. While the amount of clear material that may be produced from a log is influenced to some extent by sawing procedure, it is largely pre-determined by $\log$ size and the amount of defect present. Thickness, a major aspect of grade, is, on the other hand, directly dependent on the basic accuracy of the sawmill and the precision with which it is operated and maintained.

Grade lumber may be produced in a number of thicknesses ranging from ${ }^{3 /}$ inch to 6 inches. According to the rules of the National Hardwood Lumber Association, ${ }^{1}$ each thickness class must be full thickness in the portions of the board used to determine the grade. For example, a 5/4-inch ( $1 \frac{11}{1}$ inch thick) board that has sufficient clear area for a $\# 1$ Common but is not full thickness in the cutting areas used to determine the grade would be graded as a $4 / 4$-inch ( 1 inch thick) $\neq 1$ Common board. Many mills insure against "thin" board production by sawing lumber that is slightly thicker than is generally necessary, a practice that results in volume loss at the sawmill and a waste in remanufacturing since the excess is planed off in bringing the board to a standard surfaced thickness.

Excessive variation in thickness also affects the quality of lumber. If thickness of a hardwood board is not uniform, it will be classified as miscut and cannot be sold as a graded board. The maximum variation allowed in 4/4-inch lumber is 倠 inch between the thickest and thinnest sections of the board. Thickness is measured at the thinnest cutting used to establish the grade. Excessive thickness variation is often not readily apparent at the time of sawing, but when the lumber is measured and graded, it results in a monetary loss to the sawmill operator.

${ }^{1}$ Rules for the Measurement and Inspection of Hardwood Lumber, Cypress, Veneers and Thin Lumber. National Hardwood Lumber Association, Chicago, Illinois, January 1963-January 1964. 
With the increasing cost of proclucing lumber together with the present emphasis on lumber quality, the sawmill operator must make every effort to control the dimension of lumber.

The purpose of this report is to discuss the use of quality control charts as a means of controlling the thickness variation in the production of hardwood lumber.

\section{The Nature of Variation in Lumber Thickness}

Before discussing control charts in detail, consideration should be given to some of the factors involved in thickness rariation. The ideal situation would be to have a sawmill that could be so adjusted and operated that in sawing to a given dimension every board would have exactly the same thickness. No production process, however, is good enough to produce all products exactly alike. Even under the most carefully controlled conditions, some variation will exist even though it is not sufficient to cause rejection of the product. In the case of lumber thickness, the variation may appear in two ways. First, the average thickness of individual boards may vary, and secondly, there may be a variation in thickness within individual boards. It is these two types of variation with which the sawmill operator must contend and decide if they are being held within reasonable limits. If variation is large, the mill is usually operated so that the boards sawn have a high average thickness to insure that most of the boards will be thick enough to meet minimum specifications. The magnitude of the variation that occurs depends on the condition of the sarmill and the accuracy with which it is operated. If a sawmill is well maintained and operated, the variation that occurs is small and will be due largely to chance. Chance variation is inherent in any production process, and, unless the process is made more precise, this type of variation cannot be reduced. Fortunately, there are methods which may be used to determine whether variation other than that due to chance is occurring. If such variation does occur, its source can frequently be located and corrective measures initiated. If all the variation is clue to chance alone, the process is said to be in statistical control.

Figure 1 shows a stack of 200 boards produced by a single sawmill. All boards of the same average thickness are piled one on top of the other. A frequency distribution of this type is a way of showing graphically the accuracy of a producing unit. The average thickness of the 200 boards is 35.7 thirty-seconds of an inch or slightly under $1^{1 \%}$ inches. (Most

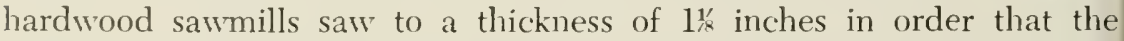
lumber will be 1 inch thick after air drying.) The range or spread of average thickness of individual boards is from 31 to 42 thirty-seconds of 


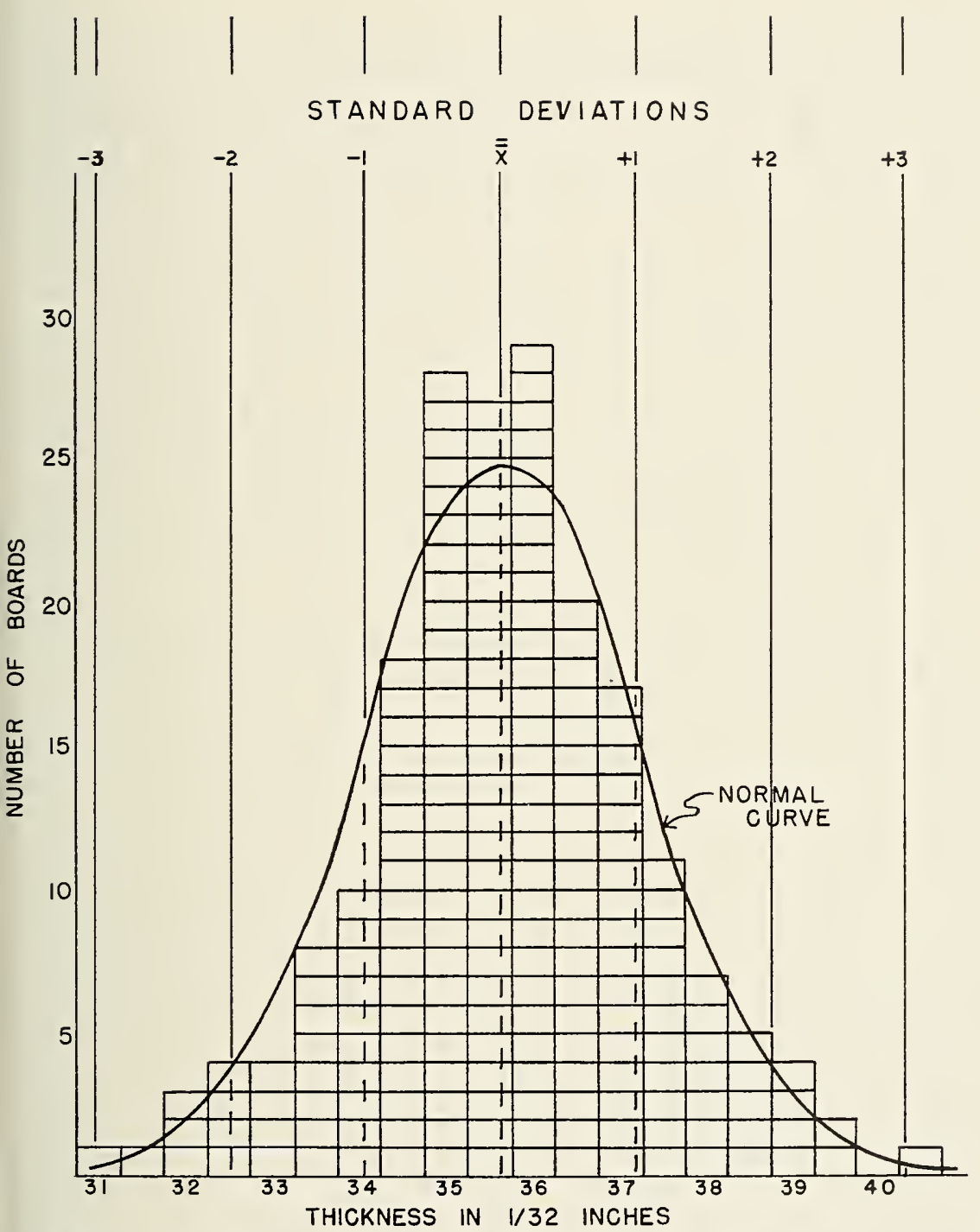

Figure 1. Distribution of board thickness produced by a sawmill operating in control.

an inch. This is a range of 11 thirty-seconds of an inch or approximately 5.5 thirty-seconds of an inch thickness variation of individual boards above and below the average thickness.

Over a long period of years, the laws which govern occurrences of particular events based on pure chance have been accurately developed. These laws, while applying exactly only to chance occurrences, also 
apply with considerable accuracy to distributions of measured values such as the thickness of lumber.

The bell-shaped curve which has been superimposed on the pile of boards shown in Figure 1 is known as the normal probability curve, and it can be plotted by mathematical methods for any frequency distribution of the type with which we are concerned. The way that the curve fits the measured values determines whether or not the population of boards is normal. If the curve fits the population, the population is said to be normal and the process is in control. If the curve does not fit the population, it is not nomal, and physical changes will be necessary to bring the mill into control. It is evident from Figure 1 that the high point of the curve is determined by the average board thickness and that the individual boards are arranged (according to thickness) on either side of the average. In a process which is operating in control, the dispersion on spread of the individual values about the average is adequately measured by a quantity called the standard deviation (in this case, the standarc deviation of the average, since each thickness measurement is the average of four measurements which were made as shown in Figure 4). While the theory behind the standard deviation is complex, its value can be easily approximated with tables and very simple calculations, as will be showr later. The utility of the standard deviation lies in the fact that it indicates how the individual boards are distributed when the only source of varia tion is due to chance.

If, for example, a sawmill is in perfect control, we can assume tha about 68 per cent or approximately two-thirds of the boards will have thicknesses within one standard deviation either above or below the average thickness. About 95 per cent of the boards will fall within twe standard deviations above and below the average thickness, and only 0 : per cent will fall outside of three standard deviations. Therefore, we cal assume that 68 per cent of the 200 boards will have thicknesses of 35 . thirty-seconds of an inch plus or minus 1.6 thirty-seconds of an inch o that they will fall within the thickness range of 34.1 to 37.3 thirty-second of an inch. Ninety-five per cent of the 200 boards will fall within twe standard deviations or within the thickness range of 32.5 to 38.9 thirty seconds of an inch, and 99.7 per cent will fall within three standar deviations or between 30.9 and 40.5 thirty-seconds of an inch. Standar deviations are shown in Figure 1 as vertical lines on both sides of th average thickness. If only 0.3 per cent or three out of every 1,000 board sawed can be expected to fall outside of three standard deviations for sawmill that is operating in control, then in 200 boards less than on board should fall outside of these same limits. Referring to Figure $1, n$ boards fall outside of these limits. Thus it may be assumed that the mi which produced these boards was operating in control. 


\section{The Preparation and Interpretation Of Quality Control Charts}

Some of the questions that must be answered if thickness is to be adequately controlled are:

1. Is the mill operating in control?

2. If the mill is not in control, how can it be brought into control?

3. If the mill is operating in control, can the average board thickness be reduced and still allow the product to meet specifications?

The most suitable tools to use for providing answers to these questions are quality control charts. While several types of control charts are available, the two of most value to the sawmill operator are the chart for averages and the chart for ranges. The chart for averages is commonly referred to as the "X chart" and the chart for ranges as the "R chart."

\section{THE SELECTION AND MEASUREMENT OF SUBGROUPS}

Before control charts can be constructed, the thickness of a number of boards (a sample) must be measured. The sensitivity of the control charts is dependent upon the accuracy of the measurements of thickness, which in turn is dependent on how closely the thickness can be gaged at the savmill. In most cases, thickness should be measured to the nearest one thirty-second of an inch in order to show variation patterns on the control charts. Since a board can vary in thickness from end to end as well as from one edge to the other, measurements must be taken in such a manner that they will show the variation if it occurs. At least four measurements are necessary to provide a satisfactory picture of the thickness variation that occurs within a board. In order to measure variation both along and across the board, measurements should be taken as shown in Figure 4. From these measurements, the average thickness and range in thickness of the individual boards may be obtained. Four measurements of each board will provide sufficient information for practical applications of control charts. In addition, the distribution of averages of four values is essentially normal, something which is not true of averages of less than four values.

An initial sample of approximately thirty to forty boards (subgroups) will ordinarily provide sufficient data for the construction of trial control charts. ${ }^{2}$ Since the control charts will be used to tell whether or not excessive variation in lumber thickness is occurring, the subgroups should be selected in such a way that data are obtained over average

²Grant, E. L., Statistical Quality Control, McGraw Hill Inc., New York, 1946. 
operating conditions. It is essential that the subgroups be selected at random to eliminate the possibility of any bias in the sample. Four or five boards may be selected at random each day until a large enough sample is obtained. The more subgroups on which the trial control charts are based. the more accurate they will be in portraying the operation, but the cost will also become greater.

\section{THE CHART FOR AVERAGES}

The control charts for averages show how much the average thickness of individual boards varies from the average thickness of all boards in the sample. The arerage thickness of individual boards $(\bar{X})$ is obtained by dividing the sum of the four thickness measurements by four. When all of the $\bar{X}$ values have been computed, their sum is divided by the total number of boards to obtain $\overline{\bar{X}}$, the calculated average thickness of all boards.

Figure 2 shows the development of a control chart for averages for the 200 boards that have been used as an example in the previous discussion. The vertical axis of the chart is marked off in units of one thirtysecond inch. The value of $\overline{\overline{\mathrm{X}}}$ (the average thickness of all 200 boards) is located on this axis and is the solid center line of the chart. The control limits are placed at three standard deviations above and below the line representing the average thickness and are drawn as broken lines to indicate that they are control limits. The method of computing the values of the control limits will be discussed subsequently. The X's on the chart indicate average thicknesses of individual boards (subgroups) and are numbered along the horizontal axis and plotted in the same order as that in which they were measured. Only a few of the individual measurements have been plotted to illustrate the $\bar{X}$ chart. The chart gives a graphic picture of the thickness variation from board to board. As long as all or most of the points fall between the upper and lower control limits we can assume that the mill is in control and that the variation that does occur is due to chance. On the other hand, if a large number of points falls outside of these limits, the variation is excessive and should be corrected. The pattern of points on the chart, along with the raw data will, in many cases, give clues to the reason for the excessive variation, and steps can be taken to reduce it.

\section{THE CHART FOR RANGES}

The control chart for arerages ( $\bar{X}$ chart) supplies a picture of variation in average thickness from one board to another, but it does not show anything about variation within individual boards. The chart for ranges 


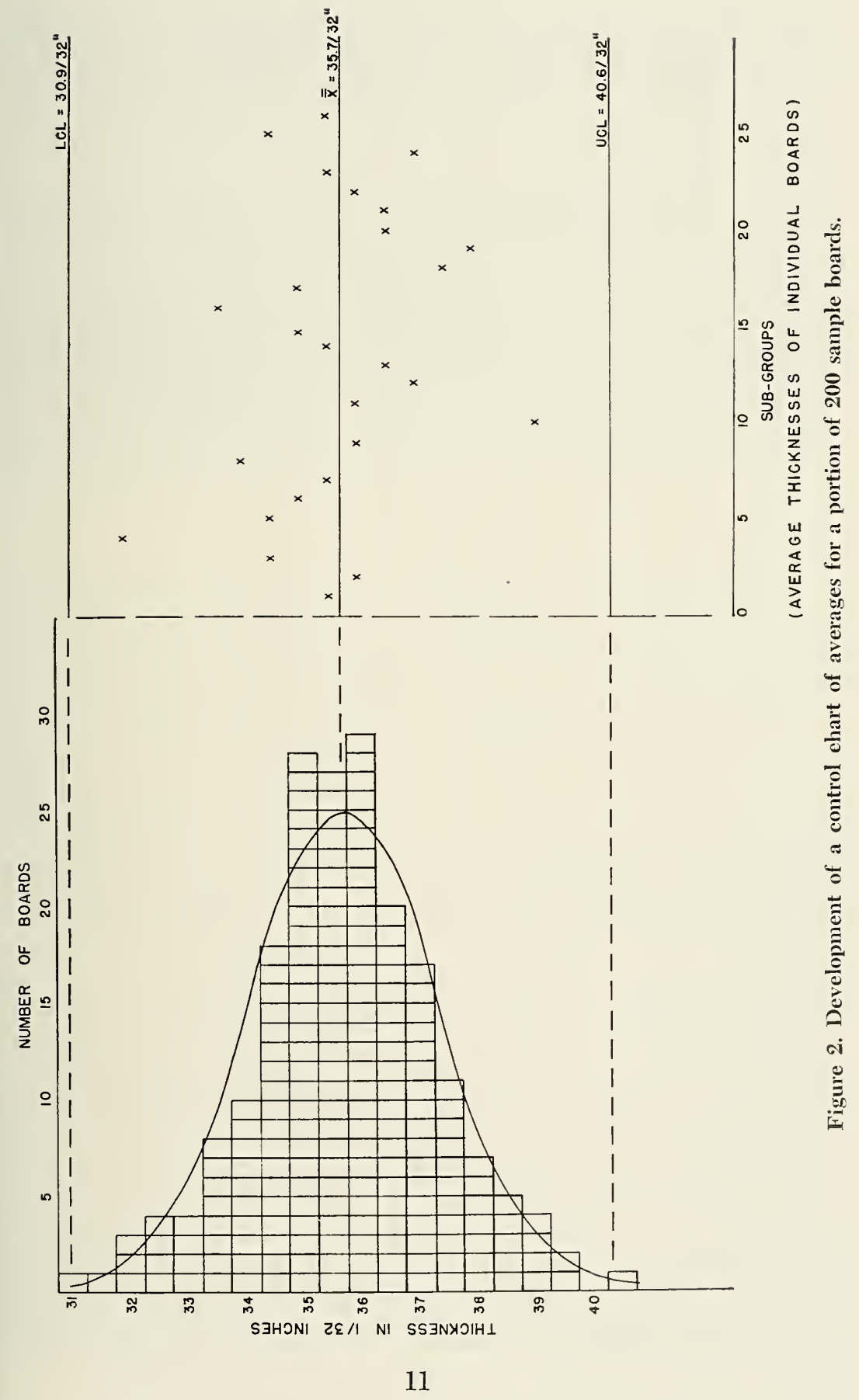


will supply this information. In determining the average thickness of each board. more than one thickness measurement must be taken. The range in thickness of each board. $\mathrm{R}$, is the difference between the thickest and thimnest measurement, and it usually varies from board to board. The ranges of all the boards in the sample are determined, added together, and the sum is divided by the total number of boards to determine $\bar{R}$, the center line of the $R$ chart.

Figure 3 shows a range chart of the 200 boards mentioned previously. The vertical axis represents variation within the board in thirty-seconds of inches. The horizontal axis shows the board or subgroup numbers corresponding to those of the $\overline{\mathrm{X}}$ chart. The middle line on the control chart labeled $\bar{R}$ represents the average range of the 230 sample board ranges. The control limits are determined on the basis of statistical theory

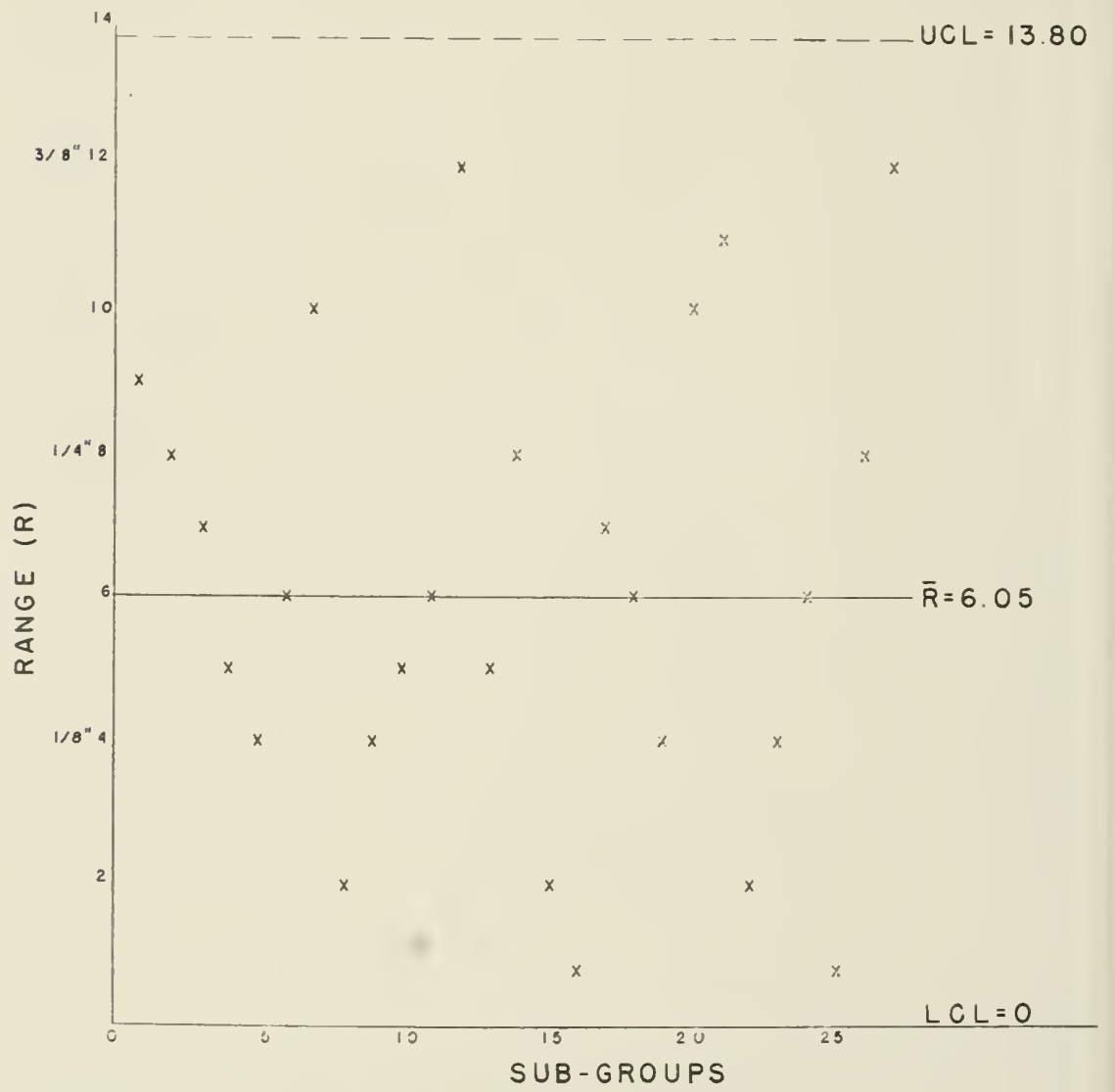

Figure 3. Control chart of ranges for a portion of 200 sample boards. 

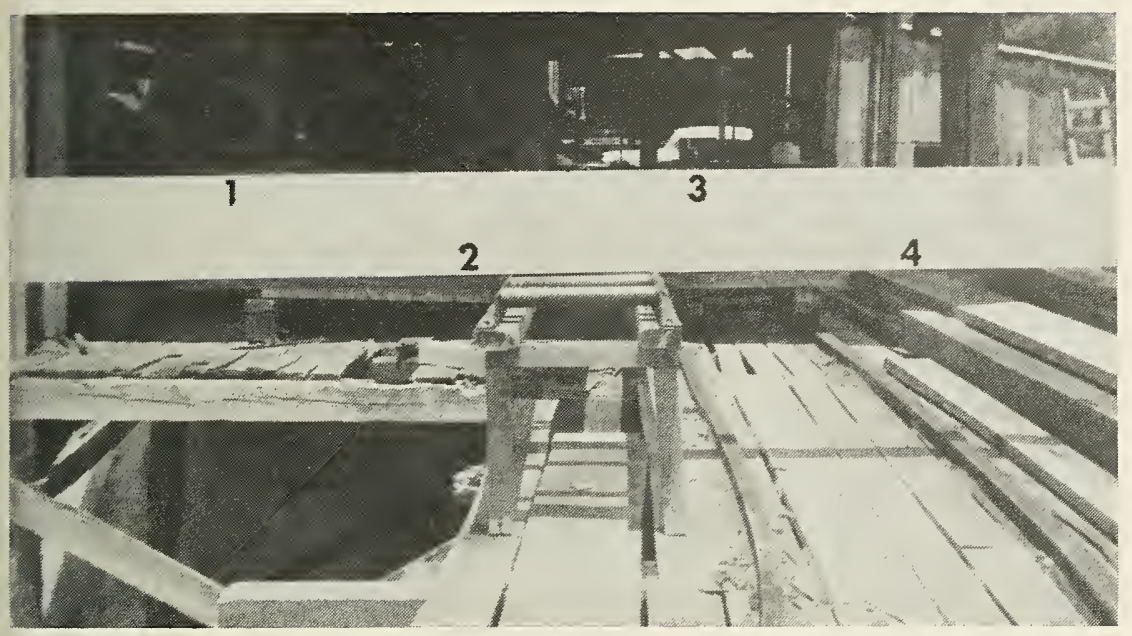

Figure 4. Four measurements were made on each board. The direction of carriage travel was from right to left.

as it applies to the distribution of individual averages about their mean or average. The same interpretation is made of points falling outside the limits of the $R$ chart as for the $\bar{X}$ chart. That is, it is expected that approximately 0.3 per cent or 3 out of 1,000 points will fall outside the limits due to pure chance. If a greater percentage falls outside the limits, then reason is provided for seeking assignable causes.

\section{CALCULATION OF CONTROL LIMITS}

The final step in developing the control charts is to determine the control limits. Essentially, control limits form a zone within which 99.7 per cent of all observed measurements will fall if the sample is taken from an entirely normal population. Such a population exists only when the $\overline{\mathrm{X}}$ values are normally distributed about $\overline{\bar{X}}$, and this occurs only when the universe or total population is normal. Since the control chart limits are determined from samples of observed data which will ordinarily not be entirely normally distributed, it is not strictly true that approximately 3 out of 1,000 observations will fall outside of the limits by chance alone. However, control charts based on observed data will rarely indicate that a process is out of control when, in fact, a state of control exists. It can be assumed that, if many points fall outside of the control limits, assignable causes of excessive variation are present.

To compute the control limits for the $\overline{\mathrm{X}}$ chart, the value for $\overline{\mathrm{R}}$ is multiplied by 0.73 . The answer obtained approximates three standard deviations when a subgroup of four is used. The upper control limit is 
the value obtained added to the value for $\overline{\overline{\mathrm{X}}}$, and the lower control limit is the value substracted from $\overline{\bar{X}}$. This is shown by equations as follows:

$$
\begin{aligned}
& \text { Upper Control Limit for } \overline{\mathrm{X}}=\overline{\bar{X}}+0.73 \overline{\mathrm{R}} \\
& \text { Lower Control Limit for } \overline{\mathrm{X}}=\overline{\overline{\mathrm{X}}}-0.73 \overline{\mathrm{R}}
\end{aligned}
$$

The upper control limit for the $\mathrm{R}$ chart is obtained by multiplying the average range $\bar{R}$ by 2.28 . The value of $2.2 S$ is a multiplier of $\bar{R}$ used to detemine the upper control limit when a subgroup of four is used. For a subgroup of six or less the lower control limit is always zero. The formulas for computing the control limits are as follows:

\section{Upper Control Limit for $\mathrm{R}=2.2 \mathrm{~S} \overline{\mathrm{R}}$ \\ Lower Control Limit for $\mathrm{R}=0$}

When the central lines and control limits have been computed and drawn on paper, the individual values of $\bar{X}$ and $R$ are plotted on the charts. The number of points falling outside of the control limits determines whether or not control exists in the manufacturing process.

\section{INTERPRETING CONTROL CHARTS}

Once the points have been plotted on the charts, it can quickly be seen whether or not a state of control exists. If all of the points fall within the control limits, the process is operating in control. It is possible, however, that the average thickness may be too high and can be reduced somewhat with all of the boards remaining above a satisfactory minimum thickness. If this reduction is made, it will increase volume at the sawmill as well as prevent waste when the lumber is planed to a nominal thickness for surfaced lumber.

The charts can indicate lack of control in three ways. First, the $\bar{X}$ chart can show lack of control with the range chart indicating control. Second, the $\mathrm{R}$ chart can indicate lack of control with the $\overline{\mathrm{X}}$ chart indicating control. Third, both the $\bar{X}$ and $R$ charts can indicate lack of control. If lack of control is indicated only by the $\overline{\mathrm{X}}$ chart, some part of the mill having to do with board to board thickness is out of adjustment. In such a case, all of the trouble may possibly be corrected by replacing worn parts or by making adjustments to the setworks. If the range chart shows control and particularly if the spread of the upper and lower limits is small, the possibility of such things as unlevel or crooked tracks, play in the mandrel or end play in the carriage trucks is practically precluded since these would tend to cause excessive variation within the board, and the $\mathbb{R}$ chart would go out of control as well. Lack of control as indicated by the $\bar{X}$ chart could also mean that there is a difference in board thick- 
ness resulting from operational mistakes. If the setworks are not operated consistently each time a board is cut, a difference in average board thickness would result.

While the $\mathrm{R}$ chart is less likely to indicate lack of control than the $\overline{\mathrm{X}}$ chart, it may occasionally do so. Any part, or parts, of the sawmill, such as end play in the saw mandrel or end play in the carriage trucks that would allow thickness variation within the board, would cause the $\mathrm{R}$ chart to go out of control. The thickness variation in such instances would be from one end of the board to the other, and the random pattern of thickness could tend to average out and make the average thickness of the board appear within the control limits on the $\bar{X}$ chart. Tracks which are not level would probably not be evidenced on the $R$ chart alone. Since the magnitude of the variation would increase each time the log was turned, variation would, in all probability, be indicated by the $\overline{\mathrm{X}}$ chart as well. The effect of the carriage knees that are out of alignment would appear in the same manner.

Lack of control as indicated by both the $\overline{\mathrm{X}}$ and $\mathrm{R}$ charts may be the result of an individual or a series of equipment or personnel problems. In many cases, a close look at the subgroup measurements to determine whether a particular pattern of variation exists will reveal the source of trouble. If this fails to give any indication, a close scrutiny of the equipment will be required to find the cause of the excessive variation in the lumber produced.

It might be well at this point to make a statement as to what constitutes lack of control when discussing control charts. Lack of control can mean different things to different people. A statistician might look at control charts and see three to ten points in a thousand outside of the control limits and call the process out of control. An individual operating the equipment on which the data were collected and who knows the capabilities of the machine might look at the same control chart and consider that the machine was operating within satisfactory limits, particularly if the limits were moderately close and points that fell outside the limits were close to them. Stated another way, a certain amount of assignable variation may exist without necessitating changes in the process operation. The desired degree of control is up to the operator, and he may feel that maintenance of practical rather than statistcal control is satisfactory.

\section{Case Studies of Quality Control Application}

Studies were made of the sawing process at five circular savmills to determine the applicability of quality control techniques for controlling thickness variation in hardwood lumber. 
Prior to measuring subgroups, a general history of each sawmill was obtained. This included information on the age, state of repair and size of the mill, and a description of accessory equipment. It was thought that these data might aid in the detection of assignable causes if excessive variation in lumber thickness occurred.

Four of the fire samills were made by the same company although they were not all the same size. They ranged in age from six months to eleven years. One was a small portable mill without any accessory equipment, having only the sawhusk and carriage and powered by a diesel engine. The other three mills of similar make had edgers, cutoffs, and two of the three had double end trimmers. Of the three, two were powered by electric motors and the third by a diesel engine. The fifth sawmill had an edger, trimmer, and, in addition, an automated electric carriage. It was also powered by electricity.

\section{MEASUREMENT OF SUBGROUPS}

Two men working together collected the data at each sawmill. The diameters and lengths of a series of logs were measured and each log was assigned an identifying number. Any unusual characteristics of the logs were noted. From this series of logs, a five to eight board sample was selected at random, depending on operating conditions and time available. After the logs had been measured and numbered, one man was positioned near the front of the mill to observe the sawing operation. A diagram was made showing the number and position of each board as the $\log$ was sawed and also which boards were put through the edger. The second man, positioned near the end of the mill, chose the sample boards and put them aside for later measurement. Figure 5 is a sample Log Data Sheet used at the sammill. By collecting data in this manner it was possible. at a later date, to reconstruct the sawing procedure for each log that contained a sample board or boards. The ability to locate the position of the sample board within the log provided another method for determining assignable causes of thickness variation.

Four thickness measurements (one subgroup) were made on each board. The four measurements were spaced a fifth of the length along the board. The first and third were made approximately an inch from the one edge; the second and fourth were made the same distance from the other edge. The four measurements (one subgroup) were always made at the same position with respect to carriage travel. The position of the first measurement was on the top. front end (passing the saw first) of the board. Measurements were made in this manner in order to show variation in thickness from edge to edge as well as from end to end. All measurements were taken with a micrometer gage and recorded to the nearest one thirty-second inch. Figure 6 shows the method of measuring. 


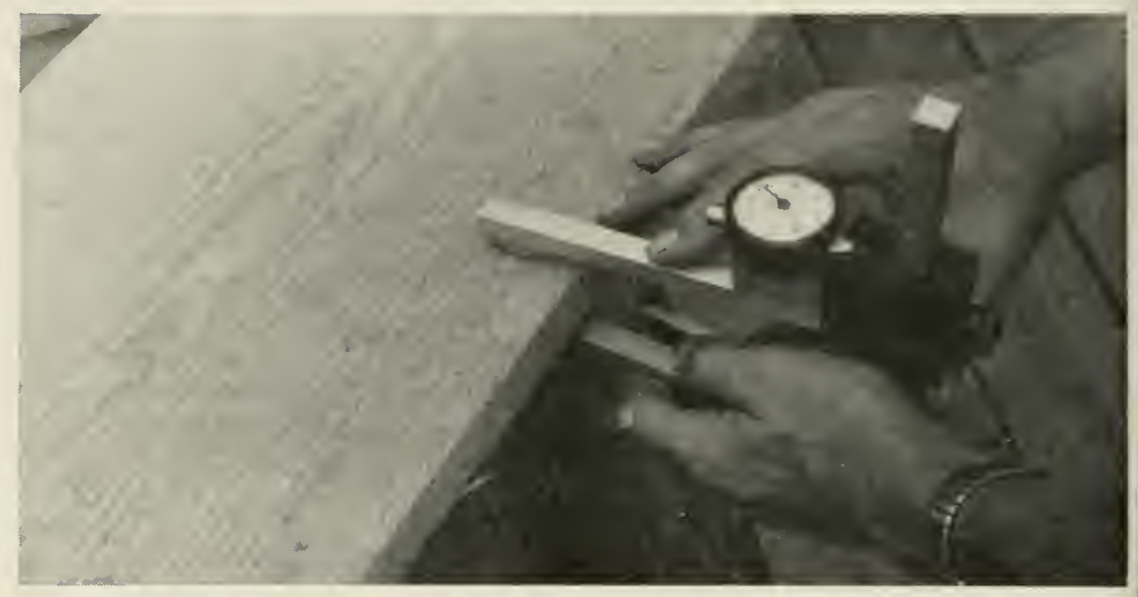

Figure 6. Measurements on the board were made with a micrometer gage to the nearest $1 / 32$ inch.

\section{TRIAL CONTROL CHARTS}

Using the data collected, trial control charts were constructed for each sawmill. Figure 7 shows compiled subgroup measurements and control limit calculations for one of the sawmills investigated. By observing the points on the control chart with respect to the control limits, it was determined whether or not the mill was in a state of statistical control. If the operation was out of control, suspected assignable causes were determined using the previously mentioned log diagrams, subgroup measurements, and sawmill history data.

After analysis of data in the office, the sawmill was revisited to show and discuss the control charts with the owner and the head sawyer. Mills that indicated lack of control were examined to locate the source of excessive variation. Changes or adjustments were then made to determine whether thickness variation could be reduced.

After adjustments had been made, another set of data was collected and control charts constructed. The continuation of the control charts. where adjustments or changes had been made, revealed whether or not the changes were sufficient to correct the cause of excessive variation. If the control charts, based on the second set of data, did not indicate control, they usually indicated possible additional changes to further im. prove the accuracy of the sawing operation.

\section{EXAMPLES OF CONTROL CHARTS}

Figure $S$ shows the control charts for Mill A. Looking at the first set of data collected ( subgroups 1 through 37 ) it may be seen that a numbe: 
Mill

A

Recorder

Jackson

Variable Thickness Unit of Measurement $1 / 32$ inch

\section{Sample}

Board

$$
\text { Location on Board }
$$

$\bar{x}$

Number

23

(Average)

$R$

(Range)

Thickness in thirty-seconds of an inch

\begin{tabular}{rllllll}
1 & 38 & 38 & 38 & 37 & 37.75 & 1 \\
2 & 37 & 37 & 38 & 37 & 37.25 & 1 \\
3 & 36 & 37 & 37 & 37 & 36.75 & 1 \\
4 & 35 & 36 & 39 & 38 & 37.00 & 4 \\
5 & 37 & 37 & 37 & 36 & 36.75 & 1 \\
6 & 36 & 37 & 37 & 36 & 36.50 & 1 \\
7 & 38 & 39 & 39 & 38 & 38.50 & 1 \\
8 & 35 & 36 & 35 & 34 & 35.00 & 2 \\
9 & 37 & 37 & 36 & 34 & 36.00 & 3 \\
10 & 36 & 34 & 35 & 37 & 35.50 & 3 \\
- & - & - & - & - & $\ldots .$. & - \\
- & - & - & - & - & $-\ldots$. & - \\
- & - & - & - & - &..- & - \\
30 & 38 & 38 & 38 & 38 & 38.00 & 1 \\
31 & 38 & 38 & 39 & 38 & 38.25 & 1 \\
32 & 37 & 38 & 38 & 37 & 37.50 & 1 \\
33 & 37 & 38 & 38 & 37 & 37.25 & 4 \\
34 & 36 & 38 & 40 & 40 & 38.50 & 0 \\
35 & 36 & 36 & 36 & 36 & 36.00 & 3 \\
36 & 38 & 37 & 35 & 35 & 36.25 & \\
\hline
\end{tabular}

$U C L \bar{x}=\overline{\bar{x}}+0.73 \overline{(R)}$

$$
\begin{aligned}
\text { Total } & R=73 \\
\bar{R} & =73 / 36 \\
& \bar{R}=2.03 \\
\text { Total } & \bar{X}=1327.25 \\
\overline{\bar{X}} & =\frac{1327.25}{36} \\
\overline{\bar{X}} & =36.87
\end{aligned}
$$$$
=36.87+0.73(2.03)
$$$$
=38.35
$$$$
L_{C L} \bar{x}=\overline{\bar{x}}-0.73(R)
$$$$
=36.87-0.73(2.03)
$$$$
=35.38
$$

$U C L \bar{r}=2.28 \bar{R}$

$=4.62$

$L C L \bar{r}=0 \quad(R)$

$$
=0
$$

Figure 7. Compiled data and calculations for $\bar{X}$ and $R$ charts for Mill $A$. 

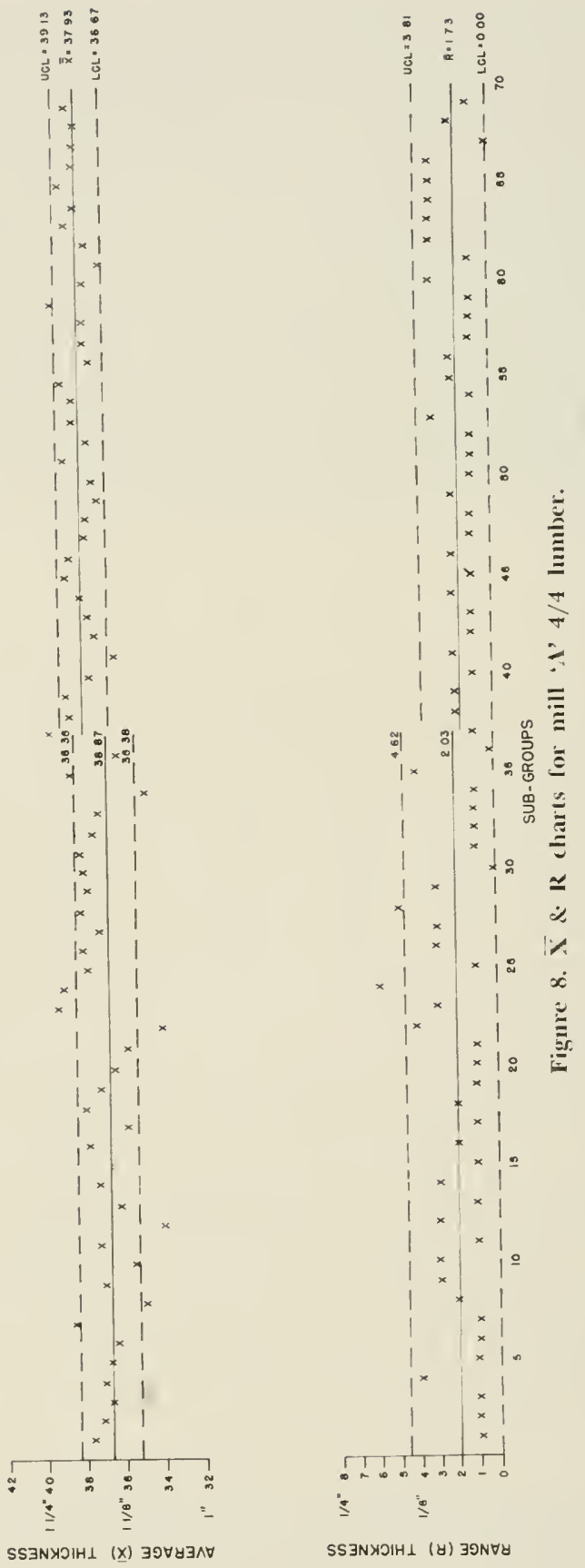
of the points on the $\overline{\mathrm{X}}$ chart as well as two on the $\mathrm{R}$ chart fall outside of the control limits. In studying the charts, some patterns are discernable. Three of the four points that are above the upper limit on the $\bar{X}$ chart represent the first boards sawed under the slab. Further observation indicates that all subgroups comprised of first boards under the slab were above the central line on the chart. The assumption was made that a lack of tension in the saw had allowed it to "crowd out" on the slab cut which tended to make the first board thick. The eleven boards (subgroups 22 to 33 ) which had thickness in excess of $\overline{\bar{X}}$ constituted a reason for suspicion. The probability of a sequence of this type happening due to chance is very small, but no specific reason for its occurrence could be determined from the data. Over half of the boards in this group had been sawed just prior to saw filing, and this may have accounted for the observed effect. The wide separation of the control limits and the fact that two points fell outside these limits on the $\mathrm{R}$ chart provided reason for suspicion that there were also other assignable causes, but the data did not indicate anything specific.

After the control charts were discussed with the sawmill owner, two changes were made. The headsaw was replaced with another saw, and the carriage ways were releveled. Additional data were then collected, and control limits were recalculated, as shown from subgroups 38 through 69 in Figure S. The average thickness as indicated by the $\overline{\mathrm{X}}$ chart is slightly high and would have required a minor adjustment to correct. Otherwise, a considerable improvement is shown. The $\mathrm{R}$ chart limits are less wide, and all points fall within the limits. The adjustments were apparently sufficient to improve accuracy of the sawing operation and bring it into control.

Figure 9 shows the control charts for Mill B, where $4 / 4$ lumber was being sawn. The target thickness for this mill was $32 / 32$ inch since the lumber was being sold as industrial blocking. Collection of data and construction of the control charts revealed that the operation was out of control. The $\overline{\mathrm{X}}$ chart exhibited a very sporadic distribution of subgroups. Many points were considerably above or below the control limits. The $\mathrm{R}$ chart, with a moderate separation of control limits, indicated that the within board variation was satisfactory. This mill was subsequently destroyed by fire and, as a result, the study was terminated. Later, it was discovered that the head sawyer had estimated the thickness with the setworks each time he sawed a board rather than pulling to a pin on the setworks quadrant. This could account for the variation in the board to board thickness. If the sawyer had been pulling to a pin, in all probability the charts would have indicated a reasonable state of control since all the data seemed satisfactory, and the mill was well set up and maintained. 

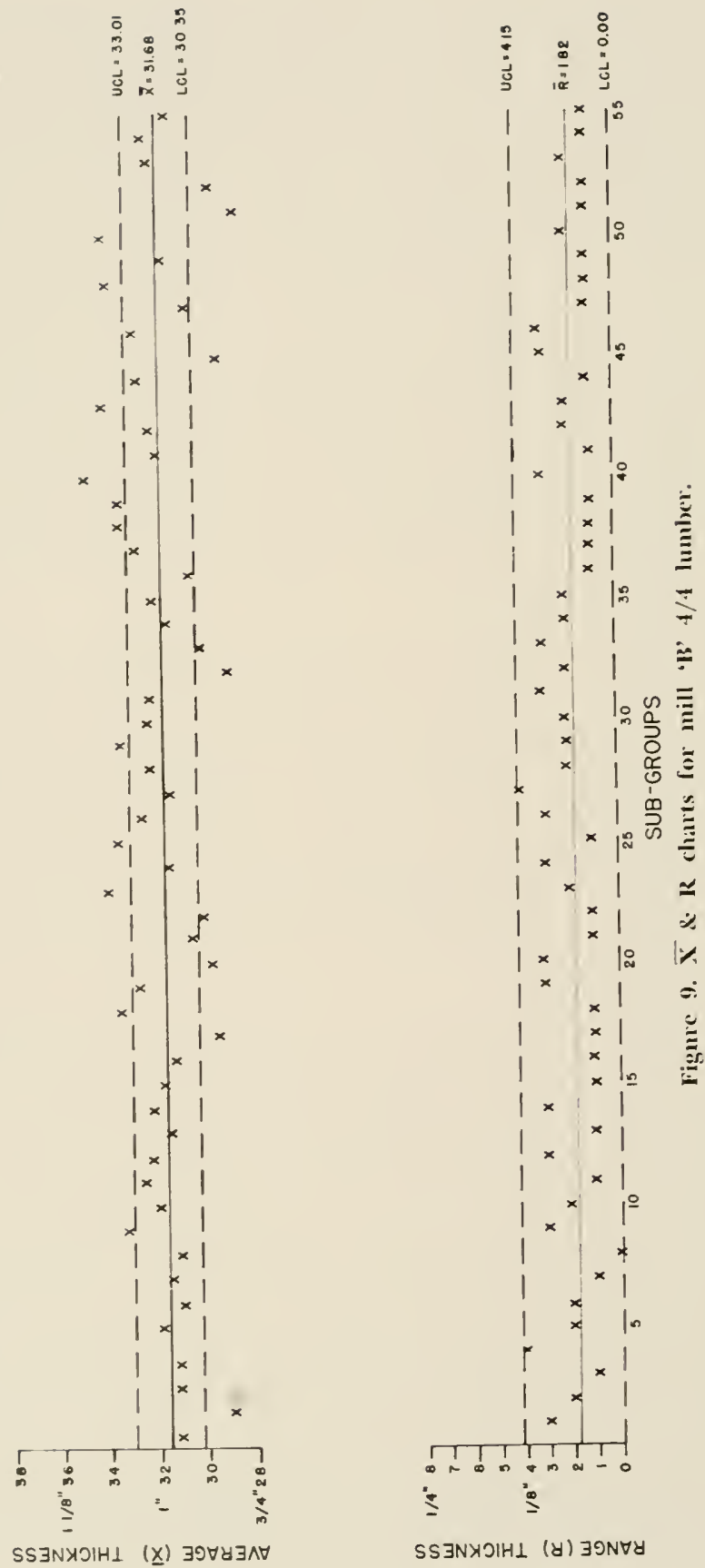

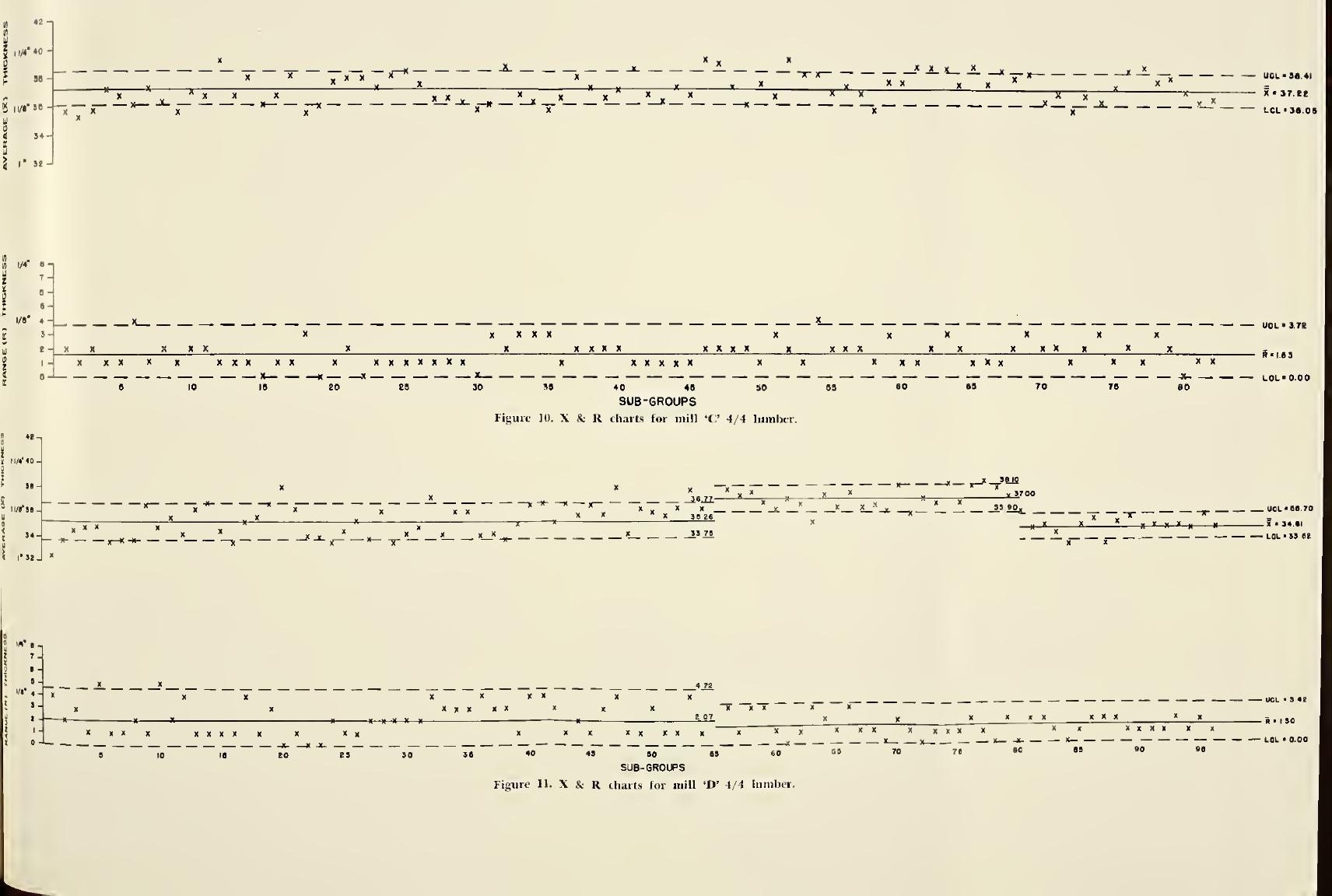

A situation similar to that encountered with Mill B is depicted by Figure 10, the control chart for Mill C. Again, the $\overline{\mathrm{X}}$ chart indicates lack of control but not the $\mathrm{R}$ chart. The $\mathrm{R}$ chart control limits for this mill were more narrow than those of the preceding one, again indicating that the mill was quite satisfactory with regard to the within board variation. A discussion of the control charts with the sawmill operator and a subsequent inspection of the mill revealed that the keys coupling the pinions to the setworks shaft were quite worn, thus allowing considerable motion of the pinions. This motion became more evident as the keys approached the top of the shaft and allowed end play in the headblock knees with resultant thickness variation. With the carriage empty, the setworks lever was pulled a number of times, and the distance the knees moved each time was measured. Considerable variation was observed, ranging from $40 / 32$ inches to 48/32 inches (including both saw kerf and board thickness). New parts were ordered for the mill but were not received during the course of the study.

Figure 11 shows the control charts for Mill D. The mill was fairly new, and, at the time the first data were collected, it had not been completely adjusted. The arrangement of the first 55 subgroups indicates that the operation was in less than satisfactory control. One of the major sources of trouble was inability to get the headsaw to operate properly. The saw was miscutting to the extent that the average between and within board thicknesses varied considerably. An electric saw sharpening device was installed, and other general adjustments were made. As a result, considerable improvement was noted, as indicated by subgroups 56 through 80 . The improved saw filing method was the largest single factor in correcting the trouble. The distance between the limits was considerably reduced on both charts, especially the $R$ chart, indicating that the improvement had been sufficient to put the mill in a reasonable state of control. At subgroup 80 a change in the $\overline{\mathrm{X}}$ chart may be noted. The average board thickness preceding subgroup 80 is slightly high. Adjustment of the setworks resulted in a reduction in average thickness but had no appreciable effect on the $\mathrm{R}$ chart. The average thickness after adjustment was slightly low and should have been raised to insure that all of the boards would be sufficiently thick after air drying.

The trial control charts constructed for Mill $\mathrm{E}$ indicated that the mill was in a poor state of control. This is shown by the first 70 subgroups of Figure 12, which illustrates the control charts for this mill. Study of the data and an inspection of the mill revealed three sources of trouble. First, there was end play in the carriage axles that allowed the carriage to shift as it passed the saw. Second, the center section of ways was out of level, which resulted in slightly wedge-shaped boards. A shim 

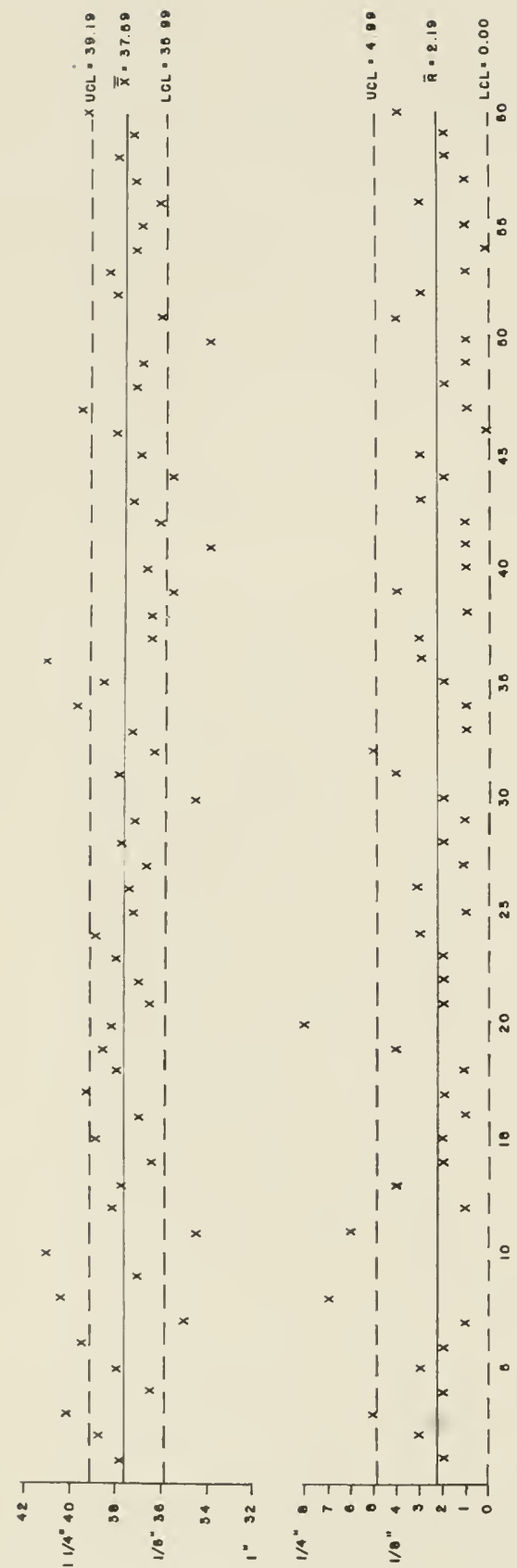

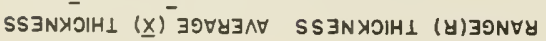

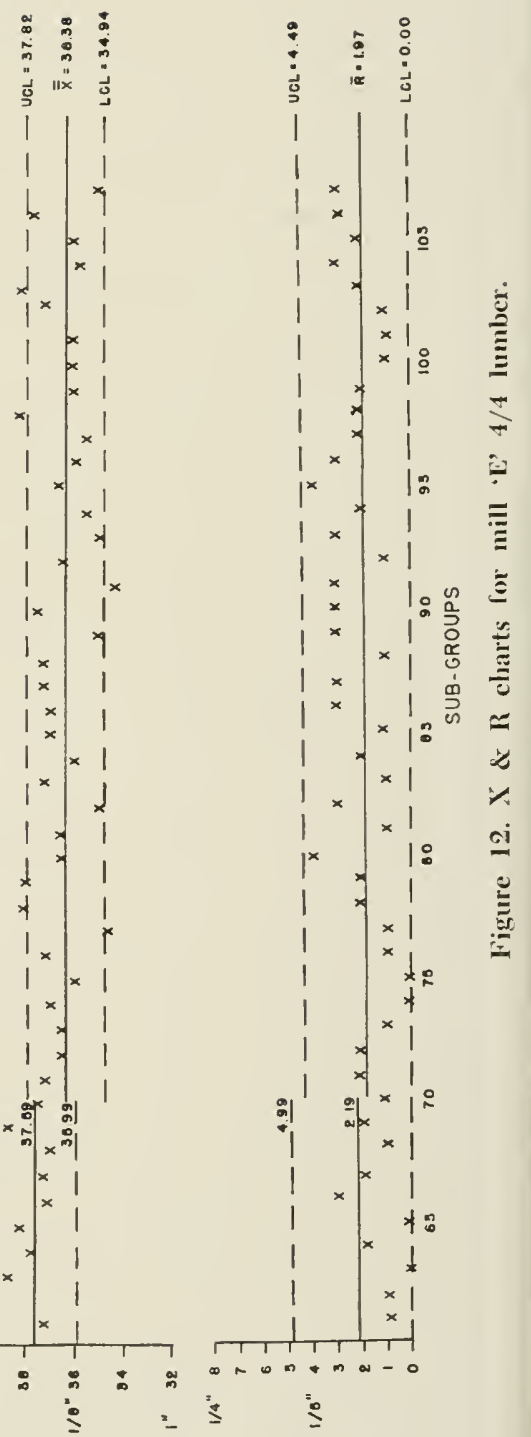

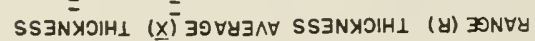


under the mud sill had slipped out and allowed the section of ways to settle as the carriage passed the saw. Third, there was a slight crook in the guide rail of the center section of ways that would make the boards thin in the center. This effect became more pronounced with increasing log length.

Two of the sources of variation were corrected. The play was removed from the carriage axles, and the center section of ways was releveled. This improved the situation somewhat, as shown by subgroups 71 through 107 (Figure 12), but did not bring the operation into a state of control. There were still too many points falling outside the limits of the $\overline{\mathrm{X}}$ chart, and although no points fell outside the limits on the $\mathrm{R}$ chart, these limits were still rather wide. It was felt that had the guide rail been straightened also, the mill would have shown a satisfactory state of control.

\section{DISCUSSION}

The use of control charts proved effective in helping to locate sources of excessive variation in lumber thickness. In the mills where adjustments were made and the control charts continued, improvements in the quality of the lumber produced were noted. While the objective of the study was not to set thickness standards, but rather to determine basic capabilities and to set limits that could be attained by a particular mill, it was found that in most cases, the limits could be narrowed. Also, the average board thickness could be decreased, thus resulting in a saving in raw material. While it is true that the reduction in average board thickness will result in the production of additional boards from a given quantity of logs, the most significant benefit arising from the use of control charts will result by reducing the number of miscut boards that cannot be sold as graded lumber. Also, well-manufactured lumber of uniform dimension should have additional value when put on the market for sale.

Control charts are simple to use and require little additional expenditure of funds. Once trial control charts have been established and control obtained, infrequent measurements, two or three per day, will be sufficient to determine whether control is maintained. The savings obtained should more than offset the expense involved in collecting, tabulating, and interpreting data.

\section{Literature Cited}

1. Bethel, J. S., A. C. Barefoot, and D. A. Stecher. 1951. Quality control in lumber manufacture. Proceedings of Forest Products Research Society. Vol. V, p. 26-31.

2. Bethel, J. S., and R. M. Carter. 1950. Techniques in hardwood plywood quality control. Proceedings of Forest Products Research Society. Vol. 4, p. 162-169. 
3. Chapman, C. V. iy50. Quality control in fumiture production. Proceedings of Forest Products Research Society. Vol, 4, p. 170-179.

4. Office of Production Research and Development. Quality Control Report No, 11. 1945. Bibliography on statistical quality control.

5. Shewhart, W. A. 1931. Economic control of quality of manufactured product. D. Van Nostrand Company, Inc., New York.

6. Simon, L. E. 1941. An engineer's manual of statistical methods. John WViley \& Sons, Inc., New York. 
5

踏

19.60

(1) 